\title{
Comparison of life quality between geriatric patients who underwent reconstructive surgery and obliterative surgery for pelvic organ prolapse
}

\author{
Suna Yıldırım Karaca® ${ }^{\circledR}$, İbrahim Egemen Ertaş® \\ Department of Obstetrics and Gynecology, Izmir Tepecik Education and Reseach Hospital, Izmir, Turkey
}

\begin{abstract}
Objectives: Pelvic organ prolapse (POP) adversely affects women's quality of life. The aim of this study is to compare the life quality after obliterative surgery and reconstructive surgery for geriatric patients with advanced pelvic organ prolapse. Material and methods: This matched case control study included sexually inactive women aged 65 years or older who had vaginal surgery for pelvic organ prolapse in Tepecik Education and Research Hospiltal between August 2012 and June 2019. Life quality of women who had undergone obliterative or reconstructive vaginal surgery were evaluated and then compared by Turkish validated prolapse quality of life questionnaire (P-QOL). Patients in obliterative and recontructive surgical procedures were matched according to age, body mass index and POP stage and each group included 49 women. Results: $\mathrm{P}-\mathrm{QOL}$ scale domains, including prolapse impact ( $26.6 \pm 12.1$ vs $34.1 \pm 16.2 ; \mathrm{p}=0.01$ ), physical/social limitations $(28.3 \pm 12.8$ vs $34.8 \pm 14.4 ; p=0.02)$ and severity measures $(24.9 \pm 12.6$ vs $30.5 \pm 13,4 ; p=0.035)$ revealed significantly lower postoperative deterioration in the obliterative group. No significant difference was found in other $\mathrm{P}-\mathrm{QOL}$ domains. The mean operation time in the obliterative group was shorter than the reconstructive group (respectively; $69.2 \pm 21.5 \mathrm{~min}$, $79.7 \pm 29.4, p=0.04$ ). There were no significant differences in estimated blood loss, length of hospital stay and intraoperative complications.

Conclusions: Obliterative surgery is a suitable option in the treatment of advanced pelvic organ prolapse in elderly patients. Key words: gynecologic surgery; pelvic organ prolapse; quality of life; urogenital prolapse
\end{abstract}

Ginekologia Polska 2021; 92, 10: 695-700

\section{INTRODUCTION}

As life duration for women increases, pelvic floor disorders become a more evident and challenging health and social issue. Due to the increasing prevalence of the elderly population, the diagnosis of pelvic organ prolapse (POP) is increasing over time. According to the US data, by 2030, more than $20 \%$ of the population will be over 65 and the number of women over the age of 84 will double [1]. Since the prevalence of pelvic organ prolapse in postmenopausal women is $41 \%$, it is important to increase the clinical awareness about the treatment of this problem [2].

The current surgical management for POP includes reconstructive and obliterative procedures [2, 3]. The goal of reconstructive vaginal surgery for POP is either the correction of the anatomic defects, or the restoration of the anatomical vaginal support. In contrast to the reconstructive surgeries, obliterative vaginal surgery is suitable for older women with advanced prolapse and no sexual expectations for future life [4].

The main purpose of the surgical procedures for women with genital prolapse is to increase the quality of life. Although there are studies in the literature evaluating the effects of obliterative and reconstructive surgery on the quality of life, these case-control studies have serious limitations due to unmatched demographic and clinic confounders including age, body mass index (BMI) and sexual activity [5-7].

The aim of this study is to compare the effect of obliterative and reconstructive vaginal surgeries on quality of life of women aged 65 or older with POP after matching samples in terms of age, urinary incontinence, sexual intercourse and BMI.

Corresponding author:

Suna Yıldırım Karaca,

Department of Obstetrics and Gynecology, Izmir Tepecik Education and Reseach Hospital, Izmir, Turkey

phone: +9005075930282

e-mail: drsunayildirimkaraca@gmail.com 


\section{MATERIAL AND METHODS}

This retrospective case-control study was conducted at Izmir Tepecik Education and Research Hospital and approved by the hospital Ethics Committee (Registration number: 2020/11-2). The sample of the study consisted of 65 years old or older, sexually inactive women who underwent obliterative colpocleisis surgery or reconstructive vaginal surgery for POP between August 2012 and June 2019.

We reviewed the computer-based medical records for preoperative medical history, preoperative POP-Q score, sexuality status, operative notes and postoperative complications for each participant. All of the patients had advanced stage uterine prolapse or vaginal vault prolapse accompanied by cystocele and rectocele. The patients who had concurrent anti-incontinence surgery or laparoscopic and laparotomic interventions were not included.

There were 71 women who had undergone obliteravite surgery and 201 patients who had undergone reconstructive surgery meeting all of this criteria. Patients in both groups were later contacted by phone. First, we questioned the participants' symptoms associated with urinary incontinence. Since the quality of life of patients with incontinance symptoms could be adversely affected, these patients were excluded from the study. In the two groups, 53 and 160 patients were respectively accessible and agreed to respond to the PQOL. We were able to match 49 of 53 patients in the obliterative surgery group and 49 of 160 patients in the reconstructive surgery group according to age, $\mathrm{BMI}$ and POP stage (Fig. 1).

\section{Quality of Life}

The effect of pelvic floor function on quality of life after surgery was evaluated with a Turkish validated prolapse quality of life questionnaire (PQOL) [8]. It determines the effects on the quality of life and evaluates the results of the treatment in women with urogenital prolapse. In addition, PQOL is an easy-to-understand, reliable method and characterizes the prevalence of symptoms. PQOL scores in all of the components included general health perception, prolapse impact, role limitation, physical/social limitations, personal relationship, emotional status, sleep/energy and severity measures.

All the participants were asked to complete a verbal questionnaire P-QOL. To evaluate the symptoms of genital prolapse, a four-point scoring system was used for each question in the questionnaire. The score ranged from no, little, moderate, or much. In calculating the P-QOL subscale scores, the scores of each individual were adapted to a scale of $0-100$ using the conversion formulas. As the total score in the questionnaire increases, the deterioration in the quality of life of the patient increases. In other words, a low score indicates a better quality of life.

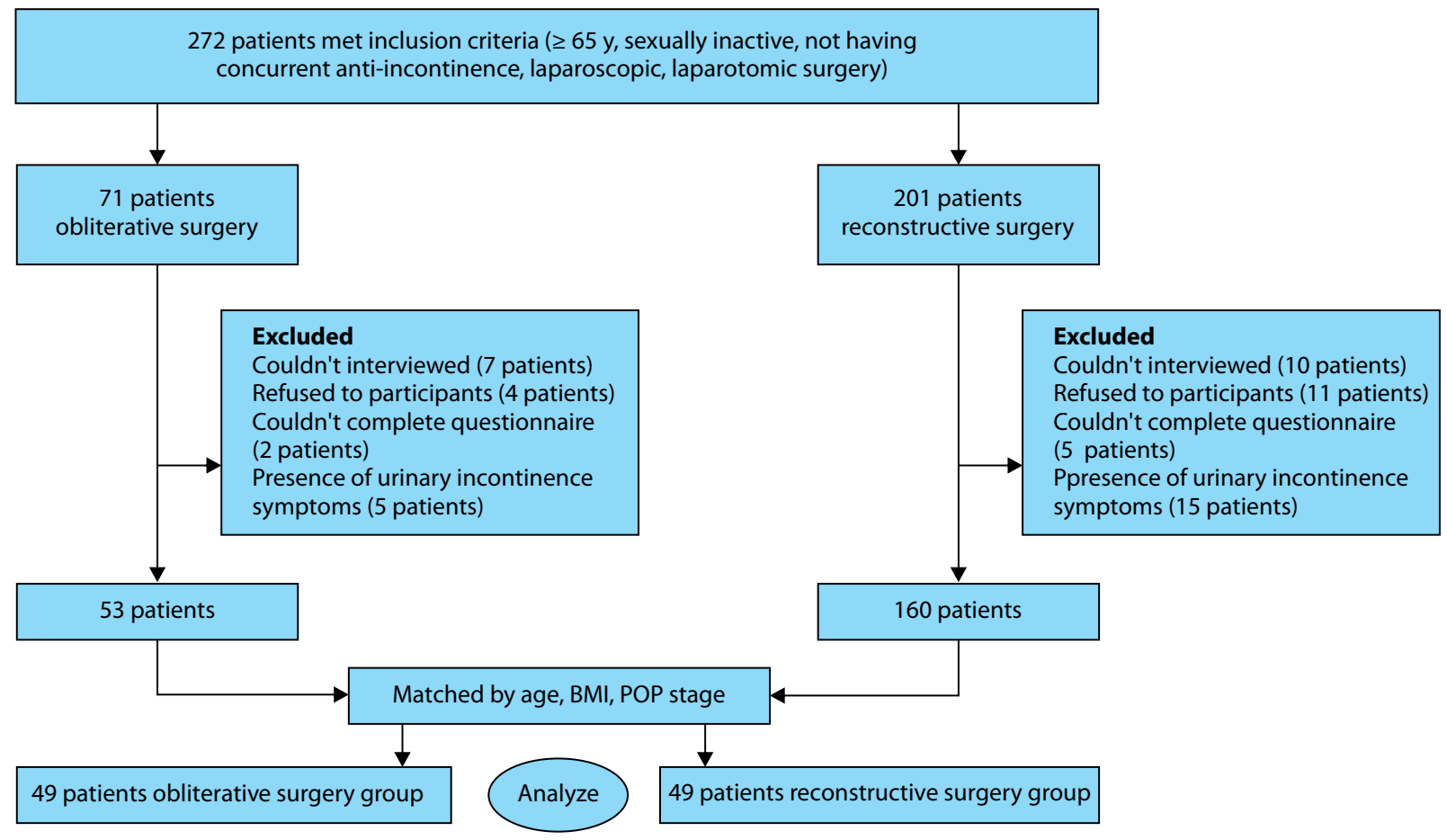

Figure 1. Flow chart of the study; BMI — body mass index; POP — pelvic organ prolapse 


\section{Description of surgery}

We inform the patient in detail about both procedures and discuss their potential benefits and risks.

In obliterative surgery (Colpocleisis), vaginal epithelium is dissected from the anterior and posterior compartments and removed up to the urethrovesical junction. Partial colpocleisis is defined as the partial removal of the anterior posterior vaginal epithelium up to the urethrovesical junction and the creation of a longitudinal tunnel from the lateral epithelium of the vagina. The purpose of creating the tunnel is to allow drainage for postmenopausal bleeding [9].

In reconstructive vaginal surgeries, sacrospinous fixation was performed after vaginal hysterectomy. In the sacrospinous ligament fixation (SSLF) procedure the vaginal apex is suspended to the sacrospinous ligament. The procedure starts with a longitudinal incision made on the posterior vaginal wall. The right pararectal space is entered by separating the vagina and rectum with blunt dissection. After the sacrospinous ligament is felt, two Breisky specula are placed. The rectum is pushed to the left. The ligament is sutured under direct vision. Sutures are passed through the vaginal apex in full thickness and tied [10].

The operation time, total blood loss and intraoperative complications of each patient were acquired from computer-based medical records.

\section{Statistical analysis}

Data were analyzed with SPSS statistical software (version 25.0; SPSS Inc., Chicago, IL, USA) and are presented as mean \pm standard deviation, median, or percentage. Chi Square test and Fisher's exact test were used for comparison of categorical data. Student's T test and the Mann-Whitney U test were used to analyze and compare continuous data among surgery groups based on the assumption of normality. Fisher-Freeman-Halton test was used to compare qualitative data. Twotailed $p$-value $<0.05$ was considered statistically significant.

\section{RESULTS}

A total of 71 patients with obliterative surgery were eligible during the study period. Seven patients could not be contacted by phone, four refused to participate, two could not complete the questionnaire and five patients reported presence of urinary incontinence symptoms. Consequently, 53 women were able to complete the questionnaire by phone interview and were included in the obliterative surgery group.

In the reconstructive surgery group, 160 out of 201 patients who met the inclusion criteria were able to complete the questionnaire. The remaining patients were matched with the patients in the obliterative surgery group according to age, BMI values and POP stage. All patients in both obliterative and reconstructive surgery group were 65 or older, sexually inactive and had stage 3-4 genital prolapse.

The demographic characteristics of the patients are shown in Table 1. The mean age was $73.4 \pm 5.4$ in the obliterative surgery group, and $72.9 \pm 5.1$ in the age-matched reconstructive surgery group. BMI values of the patients in the obliterative and reconstructive surgery group were respectively $28.4 \pm 5.6$ and $28.1 \pm 5.2$. Age $(p=0.638)$ and BMI $(p=0.784)$ variables were similar between two groups. There was also no difference in the literacy status in both groups $(p=0.545)$. The mean parity value of the patients in the obliterative surgery group was higher $(p=0.045)$.

Operative data and perioperative complications are shown in Table 2. The mean follow-up time of the obliterative and reconstructive groups were 24.8 months and

\begin{tabular}{|c|c|c|c|}
\hline Parameters & $\begin{array}{l}\text { Obliterative Surgery Group } \\
\text { (n: } 49 \text { patients) }\end{array}$ & $\begin{array}{l}\text { Reconstructive Surgery Group } \\
\text { (n: } 49 \text { patients) }\end{array}$ & p value \\
\hline Age [years] & $73.4 \pm 5.4$ & $72.9 \pm 5.1$ & 0.638 \\
\hline Body mass index $\left[\mathrm{kg} / \mathrm{m}^{2}\right]$ & $28.4 \pm 5.6$ & $28.1 \pm 5.2$ & 0.784 \\
\hline $\begin{array}{l}\text { Prolapse stage } \\
\text { Stage } 3 \\
\text { Stage } 4\end{array}$ & $\begin{array}{l}15(30.6 \%) \\
34(69.4 \%)\end{array}$ & $\begin{array}{l}15(30.6 \%) \\
34(69.4 \%)\end{array}$ & - \\
\hline $\begin{array}{l}\text { Education } \\
\text { Literate } \\
\text { Illiterate }\end{array}$ & $\begin{array}{l}17(34.6 \%) \\
32(65.4 \%)\end{array}$ & $\begin{array}{l}14(28.5 \%) \\
35(71.5 \%)\end{array}$ & $0.545^{b}$ \\
\hline Parity & $3.81 \pm 1.9$ & $3.16 \pm 1.2$ & $0.045^{a}$ \\
\hline $\begin{array}{l}\text { Medical Comorbidity } \\
\text { Cardiovaskular } \\
\text { Respiratuary } \\
\text { Endocrine } \\
\text { Other }\end{array}$ & $\begin{array}{l}10 \\
8 \\
4 \\
8\end{array}$ & $\begin{array}{l}13 \\
7 \\
3 \\
6\end{array}$ & $\begin{array}{l}0.131 \\
0.187 \\
0.293 \\
0.241\end{array}$ \\
\hline Previous prolapse surgery & $5(10.2 \%)$ & $4(8.1 \%)$ & 0.335 \\
\hline
\end{tabular}

Values are given as mean \pm standard deviation or $\mathrm{n}(\%){ }^{\mathrm{a}}{ }^{-}$- Student $\mathrm{t}$ Test; ${ }^{\mathrm{b}}$ — Fisher-Freeman-Halton Test 
Table 2. Operative data and intraoperative complications

\begin{tabular}{|c|c|c|c|}
\hline Parameters & $\begin{array}{l}\text { Obliterative Surgery Group } \\
\text { (n: } 49 \text { patients) }\end{array}$ & $\begin{array}{l}\text { Reconstructive Surgery Group } \\
\text { (n: } 49 \text { patients) }\end{array}$ & $p$ value \\
\hline Operation time [min] & $69.2 \pm 21.5$ & $79.7 \pm 29.4$ & 0.04 \\
\hline Estimated blood loss [mL] & $130.8 \pm 109.2$ & $138.3 \pm 111.2$ & 0.73 \\
\hline Length of hospital stay ${ }^{\text {a }}$ [day] & $2(1-4)$ & $2(1-5)$ & $0.56^{b}$ \\
\hline $\begin{array}{l}\text { Intraoperative complications } \\
\text { Blood transfusion } \\
\text { Bladder injury } \\
\text { Bowel injury } \\
\text { Ureter injury }\end{array}$ & $\begin{array}{c}1(2 \%) \\
0 \\
0 \\
0\end{array}$ & $\begin{array}{c}3(6.1 \%) \\
0 \\
0 \\
0\end{array}$ & $\begin{array}{l}0.24^{c} \\
\text { N/A } \\
\text { N/A } \\
\text { N/A }\end{array}$ \\
\hline
\end{tabular}

\begin{tabular}{|c|c|c|c|}
\hline P-QOL scale & $\begin{array}{l}\text { Obliterative Surgery Group } \\
\text { (n: } 49 \text { patients) }\end{array}$ & $\begin{array}{l}\text { Reconstructive Surgery Group } \\
\text { (n: } 49 \text { patients) }\end{array}$ & $p$ value \\
\hline General Health Perceptions Score & $33.1 \pm 14.5$ & $34.3 \pm 13.2$ & 0.669 \\
\hline Prolapse Impact Score & $26.6 \pm 12.1$ & $34.1 \pm 16.2$ & 0.011 \\
\hline Role Limitation Score & $32.5 \pm 13.1$ & $35.2 \pm 16$ & 0.399 \\
\hline Physical/Social Limitations Score & $28.3 \pm 12.8$ & $34.8 \pm 14.4$ & 0.02 \\
\hline Personal Relationship Score & $29.9 \pm 13.6$ & $30.5 \pm 15.9$ & 0.836 \\
\hline Emotional Score & $30.4 \pm 14.1$ & $33.8 \pm 15.2$ & 0.265 \\
\hline Sleep/Energy Score & $30.7 \pm 16.1$ & $30.9 \pm 15.2$ & 0.949 \\
\hline Severity Measures Score & $24.9 \pm 12.6$ & $30.5 \pm 13.4$ & 0.035 \\
\hline
\end{tabular}

Mann Whitney U Test; values are given as mean \pm standard deviation; P-QOL — Prolapse Quality of Life Questionnaire

31.5 months respectively. The mean operation time in the obliterative surgery group was shorter than the reconstructive surgery group $(p=0.04)$. There was no difference between the two groups in terms of the length of hospital stay $(p=0.56)$. In obliterative surgery group, the amount of blood loss was less than the reconstructive surgery group. However, the difference was not statistically significant (respectively, $130.8 \pm 109.2 \mathrm{~L}$ vs $138.3 \pm 111.2 \mathrm{~mL}, \mathrm{p}=0.73$ ) .

Quality of life scores are shown in Table 3. A high PQOL score indicates a greater impairment of the quality of life, while a low score indicates a high quality of life. There was no difference between the obliterative and reconstructive surgery groups for $\mathrm{PQOL}$ scores including general health perception, role limitation, personal relationship, emotional state, sleep/energy. However, prolapse impact $(26.6 \pm 12.1$ vs $34.1 \pm 16.2 ; p=0.01)$, physical/social limitations $(28.3 \pm 12.8$ vs $34.8 \pm 14.4 ; p=0.02)$ and severity measures scores $(24.9 \pm 12.6$ vs $30.5 \pm 13.4 ; p=0.035)$ were lower in the obliterative surgery group (Tab. 3).

\section{DISCUSSION}

Obliterative vaginal surgery appears to be a good option for the treatment of sexually inactive women with advanced age and advanced stage pelvic organ prolapse [11]. Although it is well known that obliterative vaginal surgery has better anatomical results and lower recurrence rates than reconstructive surgery, there are very few studies comparing the effect of the two surgical procedures on the patients' quality of life $[6,12,13]$. In most of these studies, the patient population in the compared groups were different in terms of age, sexual intercourse frequency, BMI and prolapse stage. However, all of these variables are relevant for the quality of life. Therefore, when designing our study, our first objective was to match the variables that affect the quality of life of genital prolapse patients in the two groups. Our results showed that obliterative surgery increases the quality of life more than reconstructive surgery in terms of the prolapse effect, physical/social limitation and severity measurement scores. For the other measures, the scores were similar. 
The generally accepted first option in POP treatment is the conservative approach [14]. However, surgery becomes inevitable in advanced POP. Studies show that both the reconstructive and obliterative surgeries significantly improve patients' quality of life. In the retrospective cohort study of Petcharopas et al, the effect of obliterative and reconstructive surgery on the quality of life was investigated and both of the surgical procedures provided an improved QOL for patients with POP. In addition, their study demonstrated that obliterative surgery provided better improvement in the prolapse domain than the reconstructive surgery [15]. In a prospective cohort study, Barber et al. [6], reported an increase in social relationships, better mental health, and less emotional problems in patients undergoing obliterative and reconstructive surgery. However these studies suffer from important limitations. In these studies, the patients in the reconstructive vaginal surgery group were younger, the groups differed in terms of the sexual intercourse status and the prolapse stages. In our study, patients in the obliterative and reconstructive procedures were matched according to age, BMI and POP stage. In addition, all patients were sexually inactive. Our study demonstrated that obliterative surgeries provides better improvement than reconstructive surgeries in the prolapse impact, physical/social limitation and severity measurement domains.

Obliterative surgery is recommended as an appropriate treatment option for sexually inactive women with advanced age and comorbid diseases [16]. However, women are mainly concerned about the permenant loss of vaginal function as it is a natural result of this procedure [17]. 67.9\% (201/296) of women who underwent reconstructive surgery in our study were sexually inactive and had no expectation of sexual life in the future. Although these patients were informed that the reconstructive procedures had higher rates of surgical complications and recurrence, they still preferred reconstructive surgery. The patients' preference for preserving their vaginal functions may be related to concerns about their post-operative femininity and body image. However, Barber et al. [6] forund no difference in body image and mood in women between women who underwent obliterative and reconstructive surgery. More importantly, they found clinically significant improvements in the quality of life in the obliterative surgery group relative to the reconstructive surgery group.

As people get older, the prevalence of comorbid diseases increases. Sixty point two percent of women in our study population had two or more chronic diseases. This rate is similar to the patients' rates in previous studies $[10,11]$. These studies report that especially in elderly patients, the type of surgery, duration of the surgery, blood losses due to the duration of the surgery increase the development of complications in the postoperative period and may lead to impaired cognitive functions $[12,13]$.

In obliterative surgery, the mean operation time was found to be significantly less than the reconstructive surgery group. The most important reason for this difference was that the patients in the reconstructive surgery group underwent hysterectomy. Similarly, Ghezzi et al. [18], compared different pelvic reconstructive surgery methods for women 75 years and older and found that reconstructive surgical procedures including vaginal hysterectomy resulted in longer operation times and more blood loss than obliterative vaginal surgeries.

In our study, we did not find any difference between the two groups in terms of blood loss and duration of hospital stay. In addition, the intraoperative complications in both groups were at low levels. We suspect the small sample size of the study might have played a role in these findings.

One strength of our study is that it has a concurrent control group and the patients in both groups are matched in terms of variables such as age BMI and prolapse level. In addition, patients in both groups were sexually inactive. Secondly, all surgical procedures were performed by a single surgeon experienced in urogynecology. Nonetheless, our study does have several limitations. Due to the retrospective design of the study, we could not evaluate the preoperative quality of life of patients diagnosed with pelvic organ prolapse. Therefore, it was difficult to evaluate the improvement in quality of life after the surgery.

\section{CONCLUSIONS}

In conclusion, our study demonstrates that despite the permanent changes in sexual function, in appropriately selected patients, obliterative surgery has a more positive effect on QOL than reconstructive surgery. Moreover, obliterative surgery does not require deep pelvic dissection, such as sacrospinosis fixation, and avoids hysterectomy. It is advisable for urogynecologists to build experience with this surgical procedure and offer it as a viable option for surgical treatment of elderly POP patients.

\section{Conflict of interest}

The authors have declared that they have no conflicts of interests in connection with this article.

\section{REFERENCES}

1. Wu J, Hundley A, Fulton R, et al. Forecasting the Prevalence of Pelvic Floor Disorders in U.S. Women. Obstetrics \& Gynecology. 2009; 114(6): 1278-1283, doi: 10.1097/aog.0b013e3181c2ce96.

2. Hendrix SL, Clark A, Nygaard I, et al. Pelvic organ prolapse in the Women's Health Initiative: gravity and gravidity. Am J Obstet Gynecol. 2002; 186(6): 1160-1166, doi: 10.1067/mob.2002.123819, indexed in Pubmed: 12066091.

3. Jelovsek J, Maher C, Barber M. Pelvic organ prolapse. The Lancet. 2007; 369(9566): 1027-1038, doi: 10.1016/s0140-6736(07)60462-0. 
4. Schweitzer KJ, Vierhout ME, Milani AL. Surgery for pelvic organ prolapse in women of 80 years of age and older. Acta Obstet Gynecol Scand. 2005; 84(3): 286-289, doi: 10.1111/j.0001-6349.2005.00677.x, indexed in Pubmed: 15715538.

5. Petcharopas A, Wongtra-Ngan S, Chinthakanan O. Quality of life following vaginal reconstructive versus obliterative surgery for treating advanced pelvic organ prolapse. Int Urogynecol J. 2018; 29(8): 1141-1146, doi: 10.1007/s00192-018-3559-9, indexed in Pubmed: 29379997.

6. Barber MD, Amundsen CL, Paraiso MFR, et al. Quality of life after surgery for genital prolapse in elderly women: obliterative and reconstructive surgery. Int Urogynecol J Pelvic Floor Dysfunct. 2007; 18(7): 799-806, doi: 10.1007/s00192-006-0240-5, indexed in Pubmed: 17111276.

7. Murphy M, Sternschuss G, Haff R, et al. Quality of life and surgica satisfaction after vaginal reconstructive vs obliterative surgery for the treatment of advanced pelvic organ prolapse. Am J Obstet Gynecol. 2008; 198(5): 573.e1-573.e7, doi: 10.1016/j.ajog.2007.12.036, indexed in Pubmed: 18455537.

8. Cam C, Sakalli M, Ay P, et al. Validation of the prolapse quality of life questionnaire (P-QOL) in a Turkish population. Eur J Obstet Gynecol Reprod Biol. 2007; 135(1): 132-135, doi: 10.1016/j.ejogrb.2007.06.009, indexed in Pubmed: 17693011.

9. Zebede S, Smith AL, Plowright LN, et al. Obliterative LeFort colpocleisis in a large group of elderly women. Obstet Gynecol. 2013; 121 (2 Pt 1): 279-284, doi: 10.1097/AOG.0b013e31827d8fdb, indexed in Pubmed: 23344277.

10. Petri $E$, Ashok K. Sacrospinous vaginal fixation--current status. Acta Obstet Gynecol Scand. 2011; 90(5): 429-436, doi: 10.1111/j.1600-0412. 2011.01084.x, indexed in Pubmed: 21306342.

11. Maher C, Baessler K, Glazener CMA, et al. Surgical management of pelvic organ prolapse in women. Cochrane Database Syst Rev. 2004(4):
CD004014, doi: 10.1002/14651858.CD004014.pub2, indexed in Pubmed: 15495076.

12. Aigmueller Th, Riss $P$, Dungl $A$, et al. Long-term follow-up after vaginal sacrospinous fixation: patient satisfaction, anatomical results and quality of life. Int Urogynecol J Pelvic Floor Dysfunct. 2008; 19(7): 965-969, doi: 10.1007/s00192-008-0563-5, indexed in Pubmed: 18246291.

13. Murphy M, Sternschuss G, Haff R, et al. Quality of life and surgical satisfaction after vaginal reconstructive vs obliterative surgery for the treatment of advanced pelvic organ prolapse. Am J Obstet Gynecol. 2008; 198(5): 573.e1-573.e7, doi: 10.1016/j.ajog.2007.12.036, indexed in Pubmed: 18455537.

14. Hagen S, Stark D. Conservative prevention and management of pelvic organ prolapse in women. Cochrane Database Syst Rev. 2011(12): CD003882, doi: 10.1002/14651858.CD003882.pub4, indexed in Pubmed: 22161382.

15. Petcharopas A, Wongtra-Ngan S, Chinthakanan O. Quality of life following vaginal reconstructive versus obliterative surgery for treating advanced pelvic organ prolapse. Int Urogynecol J. 2018; 29(8): 1141-1146, doi: 10.1007/s00192-018-3559-9, indexed in Pubmed: 29379997.

16. Bazi T. The underutilization of obliterative and constrictive surgery in the surgical treatment of pelvic organ prolapse. Int Urogynecol J. 2019; 30(8): 1221-1224, doi: 10.1007/s00192-019-03994-x, indexed in Pubmed: 31183534.

17. Takase-Sanchez MM, Brooks HM, Hale DS, et al. Obliterative Surgery for the Treatment of Pelvic Organ Prolapse: A Patient Survey on Reasons for Surgery Selection and Postoperative Decision Regret and Satisfaction. Female Pelvic Med Reconstr Surg. 2015; 21(6): 325-331, doi: 10.1097/SPV.0000000000000198, indexed in Pubmed: 26506160.

18. Ghezzi F, Uccella S, Cromi A, et al. Surgical treatment for pelvic floor disorders in women 75 years or older: a single-center experience. Menopause. 2011; 18(3):314-318, doi: 10.1097/gme.0b013e3181f2e629, indexed in Pubmed: 20861753. 